\title{
MOLECULAR EPIDEMIOLOGY OF A GEOGRAPHICALLY LOCALISED SALMONELLA TYPHIMURIUM DT104 OUTBREAK IN DANISH CATTLE AND PIGS
}

\author{
Birgitte Langvad ${ }^{1,2,3}$, Marianne N. Skov ${ }^{2}$, Erik Rattenborg ${ }^{3}$ and Dorte L. Baggesen ${ }^{2}$ \\ ${ }^{1}$ Royal Veterinary and Agricultural University, 4 Stigboejlen, DK-1870 Frederiksberg C, Denmark \\ ${ }^{2}$ Danish Veterinary Laboratory, 27 Bülowsvej, DK-1790 Copenhagen V, Denmark \\ ${ }^{3}$ Danish Dairy Board, 22 Frederiks Allé, DK-8000 Aarhus C, Denmark
}

Salmonella enterica serovar Typhimurium phage type DT 104 is a zoonotic bacteria. $25 \%$ of the S. Typhimurium cases in humans in Denmark are caused by DT104 and food of animal origin is thought to be the main source of these infections. DT 104 is found in many different kinds of animal species including cattle.

Molecular typing methods have proven to be a strong tool in epidemiological investigations.

In the present investigation pulse field gel electrophoresis (PFGE) and plasmid profiling have been the methods used to investigate a geographically localised (15 km in diameter) outbreak among cattle and pigs.

88 isolates of DT 104 samples from 15 different cattle and pig herds collected during a period of three years was characterised by plasmid profile analysis and pulsed field gel electrophoresis (PFGE) using the digestion enzymes $X b a \mathrm{I}$ and $B \ln \mathrm{I}$. The samples originated mainly from cattle but include also swine, sheep, horse, hen, dog, cat and rat. Eighty-six of the isolates were multiresistant and two were fully susceptible to antimicrobial agents.

Four different PFGE profiles were identified. 84 of the isolates were the same PFGE type. The two susceptible isolates had a different PFGE profile. Four different plasmidprofiles were found. One plasmid profile dominated in 13 of the 15 herds and another profile dominated in the remaining two herds.

The plasmid profile has demonstrated high in-vivo stability in the herds of the region. An investigation of the in-vitro stability of the plasmids showed that the plasmids were very stable with no loss over time. This may indicate that the two different plasmid profiles in two and thirteen herds, respectively, reflect two independent outbreaks with different sources of infection

The plasmid profile found in the 13 herds has not been found previously in cattle herds in Denmark though it has been found in isolates from humans, swine and food.

A majority of the herds are connected either through neighbourhood or ownership or because they share agricultural machines. In most cases, a certain route of transmission between cattle farms in the outbreak region was suspected, however, in five cases, no obvious cause of introduction at herd level was found.

The results combined with the epidemiological data available indicated that risk factors of introduction of DT104 is being neighbour to a DT104 infected farm, sharing agricultural machines or manure tank with an infected farm. 